\title{
Corrigendum
}

\section{Corrigendum to "Some Properties of Curvature Tensors and Foliations of Locally Conformal Almost Kähler Manifolds"}

\author{
Ntokozo Sibonelo Khuzwayo and Fortuné Massamba (iD \\ School of Mathematics, Statistics and Computer Science, University of Kwazulu-Natal, Private Bag X01, Scottsville 3209, \\ South Africa \\ Correspondence should be addressed to Fortuné Massamba; massfort@yahoo.fr \\ Received 27 April 2021; Accepted 27 April 2021; Published 17 May 2021 \\ Copyright (c) 2021 Ntokozo Sibonelo Khuzwayo and Fortuné Massamba. This is an open access article distributed under the \\ Creative Commons Attribution License, which permits unrestricted use, distribution, and reproduction in any medium, provided \\ the original work is properly cited.
}

In the article titled "Some Properties of Curvature Tensors and Foliations of Locally Conformal Almost Kähler Manifolds" [1], there was an error in equation (12) in which $B=$ $-\left(1 / x_{2}^{2}\right) X_{2}$ should read as $B=-X_{2}$.

\section{References}

[1] N. S. Khuzwayo and F. Massamba, "Some properties of curvature tensors and foliations of locally conformal almost Kähler manifolds," International Journal of Mathematics and Mathematical Sciences, vol. 2021, Article ID 6673918, 7 pages, 2021. 